\title{
Reforma educacional no sistema estadual de ensino: do enfraquecimento dos princípios democráticos às contradições na gestão dos processos educativos na escola pública em Goiás
}

\author{
Educational reform in the state education system: from the weakening of \\ democratic principles to the contradictions in the management of educational \\ processes in the public school in Goiás \\ La reforma educativa en el sistema educativo estatal: del debilitamiento de los \\ principios democráticos a las contradicciones en la gestión de los procesos \\ educativos en las escuelas públicas de Goiás \\ LUÍS GUSTAVO ALEXANDRE SILVA \\ http://orcid.org/0000-0002-9859-0613 \\ Universidade Federal de Goiás \\ Programa de Pós-graduação em Educação \\ Faculdade de Educação \\ Goiânia, GO, Brasil \\ RICARDO ANTÔNIO GONÇALVES TEIXEIRA \\ https://orcid.org/0000-0002-1603-2088 \\ Universidade Federal de Goiás \\ Programa de Pós-graduação em Educação \\ Faculdade de Educação \\ Goiânia, GO, Brasil
}

\begin{abstract}
Resumo: $\mathrm{O}$ artigo analisa os efeitos do processo de reforma educacional no trabalho do diretor e na gestão da escola pública pertencente ao sistema estadual de ensino de Goiás. A pesquisa utiliza como metodologia a análise de documentos oficiais, a revisão de literatura e os dados de questionário aplicado aos diretores escolares. Os resultados demonstram que a política de bônus e os procedimentos avaliativos interferem na gestão e no trabalho do diretor, mas ainda não se constituem como as principais referências responsáveis pelas decisões em substituição a práticas de gestão democrática.
\end{abstract}

Palavras-chave: Reforma. Gestão da Escola. Diretor Escolar.

Abstract: The article analyzes the effects of the education reform process on the work of the principal and on the management of the public school belonging to Goiás' state school system. The research uses as methodology the analysis of official documents, literature review and questionnaire data applied to school principals. The results show that the bonus policy and evaluation procedures interfere in the management and work of the principal, but are not yet the main references responsible for decisions in substitution for democratic management practices.

Keywords: Reform. School management. School Principal. 
Resumen: El articulo analiza los efectos del proceso de reforma educativa en el trabajo del director y la gestión de las escuelas públicas pertenecientes al sistema de educación estatal de Goiás. La investigación utiliza como metodología el análisis de documentos oficiales, la revisión de la literatura y los datos del cuestionario aplicado a los directores de escuela. Los resultados muestran que la politica de primas y los procedimientos de evaluación interfieren en la gestión y el trabajo del director, pero no se constituyen todavía como las principales referencias responsables de las decisiones para sustituir las prácticas de gestión democrática.

Palabras clave: Reforma. Gestión escolar. Director de la escuela.

\section{INTRODUÇÃO}

O presente estudo refere-se aos resultados parciais alcançados pela pesquisa "O processo de reforma educacional e os impactos sobre a gestão da escola pública no sistema estadual de educação de Goiás”. Esse artigo, em especial, tem como objetivo realizar uma breve análise dos programas Reconhecer e do Sistema de Avaliação Educacional do Estado de Goiás (Saego), constitutivos do processo de reforma educacional, instituído pelo Pacto pela Educação em Goiás e, aprofundar, a compreensão dos efeitos e consequências das políticas públicas educativas contidas na implementação do programa Reconhecer e do Sistema de Avaliação Educacional (Saego) na gestão da escola pública e no trabalho do diretor escolar.

A pesquisa origina-se de análise de documentos oficiais da Secretaria de Estado de Educação, Cultura e Esportes de Goiás (Seduce) ${ }^{1}$ destinados à formulação e implementação de políticas públicas educacionais. A análise documental apresenta-se como recurso metodológico essencial para a investigação, pois possibilita constituir um quadro conceitual, baseado em informações oficiais sobre os dados, a estrutura educacional do sistema estadual de ensino e os programas educacionais instituídos pelo governo do Estado de Goiás. Em relação aos documentos oficiais da Seduce que foram selecionados para análise, destaca-se o Programa Reconhecer e o relatório de monitoramento do Sistema de Avaliação Educacional do Estado de Goiás (Saego).

A pesquisa utiliza-se de revisão de literatura realizada por meio de consultas a banco de teses e dissertações defendidas referente ao processo de reforma educacional em Goiás. Este estudo específico, com recorte direcionado

\footnotetext{
1 A Secretaria de Estado de Educação teve seu nome alterado, no período de 2014 a 2018, para Secretaria de Estado de Educação, Cultura e Esportes (Seduce), pois incluiu as pastas da antiga Secretaria de Estado da Cultura (Secult-GO) e da Superintendência do Esporte e Lazer. No início de 2019, o atual governo renomeou a pasta como Secretaria de Estado de Educação (Seduc-Goiás). A pesquisa analisa documentos elaborados pela antiga Secretaria de Estado de Educação, Cultura e Esportes, no período de 2011 a 2018, assim, é a sigla Seduce que será utilizada no decorrer do artigo.
}

1182 - Rev. Bras. Polít. Adm. Educ. - v. 37, n. 3, p. 1181 - 1198, set./dez. 2021 
à investigação do tema reforma educacional no Estado de Goiás, cujos dados foram obtidos por meio da análise dos resumos e conteúdos completos de teses e dissertações defendidas na área educacional, assemelha-se a um "estado do conhecimento", pois se refere a um tipo de pesquisa de natureza bibliográfica, cujo procedimento metodológico é a análise sistemática e criteriosa da produção acadêmica realizada na área sobre o tema.

Após a análise documental e a revisão de literatura foram elaborados questionários com questões de múltipla escolha, para serem aplicados aos diretores de escolas públicas estaduais. As questões foram formuladas a partir de conceitos específicos de investigação provenientes do campo da gestão escolar, da avaliação e do currículo oriundos do processo de revisão de literatura. Os questionários foram elaborados na Plataforma Forms e enviados aos diretores escolares pelo e-mail institucional da Seduce em setembro de 2018. O formulário continha 80 perguntas relativas ao perfil da escola, o perfil acadêmico e profissional do diretor, a gestão da escola, o programa Reconhecer e os efeitos do Saego na gestão da escola.

A constituição da amostra relativa ao número de escolas públicas participantes da pesquisa e a quantidade de questionários a serem enviados aos diretores escolares deu-se, inicialmente, pela definição de escolas públicas estaduais vinculadas à Coordenadoria Regional de Educação, Cultura e Esporte de Goiânia (Crece-Goiânia) ${ }^{2}$. Essa coordenadoria regional reúne a maior quantidade de escolas públicas vinculadas à sua circunscrição, constituindo-se como a maior coordenadoria em número de escolas públicas estaduais do Estado de Goiás. Assim, o primeiro critério para a definição da amostra de escolas públicas estaduais participantes da pesquisa foi o pertencimento à coordenadoria regional, localizada em Goiânia, capital do Estado de Goiás, considerada como a mais representativa em comparação com as demais distribuídas no interior do Estado de Goiás.

A amostra compõe-se, posteriormente, pela definição do número de escolas públicas participantes da pesquisa em comparação com o número total de escolas públicas estaduais pertencentes à Crece-Goiânia ${ }^{3}$. A totalidade das 131 escolas vinculadas à Crece-Goiânia foram convidadas a participar da investigação científica por meio do envio do questionário, via e-mail institucional da Seduce. a tradicional estrutura administrativa da Secretaria de Estado de Educação dividida em 40 Coordenadorias Regionais de Educação, Cultura e Esporte (atuais Coordenadorias Regionais de Educação), com o objetivo de melhor distribuir a estrutura burocrática do sistema de ensino. A Coordenadoria Regional de Educação, Cultura e Esporte de Goiânia refere-se a esse órgão vinculado à Seduce responsável pela coordenação de escolas públicas estaduais do município de Goiânia.

3 A Crece-Goiânia, no período de 2018 e 2019, possuía 131 escolas públicas estaduais, distribuídas em 71 escolas públicas de tempo parcial (padrão), 34 escolas públicas de tempo integral, 7 escolas militares e 19 escolas conveniadas. 
Apesar do envio dos questionários a todas as escolas públicas pertencentes a CreceGoiânia, obteve-se o retorno de 91 questionários. Dessa forma, considerando que se trata de 1 sujeito por escola, a pesquisa contará com 91 participantes diretores escolares, número correspondente ao universo total de representatividade das escolas dessa coordenadoria regional, satisfazendo ao percentual de $95 \%$ de nível de confiança com $6 \%$ de margem de erro.

O universo de 91 escolas públicas estaduais definido como a amostra da pesquisa foi separado por tipos de escolas (padrão, integral, militar e conveniada) a partir de informações cedidas pela Seduce e concentrada por regiões, de acordo com a divisão definida no Mapa Urbano Básico Digital de Goiânia, elaborado pela Prefeitura de Goiânia (GOIANIA, 2012). Após a obtenção dos questionários respondidos pelos diretores, durante o período de Setembro de 2018 a Fevereiro de 2019, desenvolveu-se a fase de análise das informações e categorização realizada a partir do conteúdo das respostas contidas nos formulários.

\section{DESCENTRALIZAÇÃO, RESPONSABILIZAÇÃO E MERITOCRACIA EM TEMPOS DE REFORMA EDUCACIONAL}

A partir da última década do século XX, teve início um processo de reforma na estrutura administrativa do estado, cujo objetivo foi redimensionar a sua organização burocrática e instituir os princípios do paradigma gerencial, consubstanciado aos parâmetros da Nova Gestão Pública, no cerne da estrutura estatal. Com a intensificação desse paradigma, os procedimentos administrativos, próprios da iniciativa privada, dentre os quais, a eficiência, o desempenho, a produtividade e o planejamento tornaram-se cada vez mais objetos centrais da gestão pública. Nesse contexto, diversas ações foram realizadas por governos, visando intensificar o processo de descentralização, com o objetivo de transferir para a esfera local atribuições administrativas e adaptarem-se aos parâmetros gerenciais efetivados por meio da responsabilização.

No caso específico da educação, as políticas de descentralização e responsabilização estão alinhadas à dimensão financeira de repasses e prestação de contas de recursos públicos adicionais transferidos para a instituição escolar, ou a fontes de recursos provenientes de parcerias com o setor privado. Essa perspectiva de descentralização fundamentada sobre parâmetros privados estimula medidas de concessão de autonomia à rede de escolas e a semiprivatização, fenômeno que efetiva a transferência do bem social educação para a dimensão do mercado sem a presença compensatória do estado, tendo como parâmetro de classificação das escolas, o nível de desempenho dos alunos e resultados educacionais em avaliações nacionais em larga escala (MARTINS, 2001). 
Destaca-se que o processo de responsabilização se intensifica com a constituição de rigorosas políticas de avaliação e controle de desempenho, que contribui para incitar relações de competição entre os estabelecimentos e agentes escolares, o que representa, na prática, a introdução de parâmetros meritocráticos no universo educacional. A meritocracia se materializa nas práticas de gestão ao orientar uma política que se desenvolve com base na aplicação de testes em larga escala, divulgação de resultados e recompensa por meio de bonificações. $\mathrm{Na}$ prática, observa-se que as políticas de responsabilização articuladas a princípios meritocráticos interferem demasiadamente na gestão da escola, pois o discurso de maior autonomia não se efetiva quando os diretores têm que seguir as orientações dos órgãos centrais da burocracia, que determinam os índices de desempenho a serem atingidos, diminuindo o grau de intervenção do diretor e dos agentes escolares na definição das estratégias pedagógicas realizadas na escola (SANTOS; ANDRADE; MARQUES, 2019).

Segundo Maroy e Voisin (2013), os instrumentos utilizados para a implementação das políticas de responsabilização e os mecanismos que os unem uns aos outros, constituem elementos-chave de análise para a compreensão dos significados e das orientações sociopolíticas que eles operacionalizam. Tratase de um fenômeno complexo, pois, nas últimas décadas, há uma coexistência entre o modo de regulação burocrático, em transformação, baseado em normas e princípios oriundos do estado, e que se mantém por meio da intervenção da administração direta estatal e o modo de regulação pós-burocrático, em atividade, baseado em parâmetros normativos oriundos da burocracia estatal em sintonia com preceitos gerenciais de condução do serviço público. A coexistência desses modos de regulação tende a complexificar a gestão das instituições escolares e produzir efeitos contraditórios (BARROSO, 2012).

Nesse sentido, observa-se que o paradigma educacional pautado em princípios democráticos e consubstanciado no exercício da autonomia que encontrou eco na Constituição Federal de 1988, em seu artigo 206, que resguarda o princípio da gestão democrática do ensino público e na Lei de Diretrizes e Bases da Educação Nacional que corrobora o sentido emanado na Carta Magna ao estabelecer, a gestão democrática como princípio para a organização jurídica dos sistemas e estabelecimentos de ensino, perde espaço político. As conquistas jurídicas decorrentes da luta política dos educadores sofrem significativas alterações no decorrer da década de 1990, em parte manifestas na própria LDB, mas principalmente na legislação educacional posterior. Em geral, as novas propostas educacionais, com características pós-burocráticas, distanciaram-se 
demasiadamente da conotação democrático popular materializada na Constituição Federal de 1988, que instituía a educação como direito público e social (BRASIL, 2002; BRASIL, 2000).

No entanto, Barroso (2005) esclarece que no sistema educativo existe uma diversidade de fontes, de finalidades e modalidades de regulação em função da diversidade de atores envolvidos, das posições, dos interesses e estratégias de cada um deles. Para o autor, há sempre algum tipo de reajustamento dos atores às regras estabelecidas, pois a relação entre a regulação realizada pelo poder central e a ação dos atores não é linear e automática, cabendo possíveis interpretações e múltiplas regulações. Assim, apesar das induções da burocracia estatal e do significativo grau de controle exercido nos sistemas de ensino, por vezes condicionando a adesão dos agentes às políticas formuladas, o estudo sistemático das características sociais e das relações de poder pode determinar certo grau de hibridização nos diversos contextos de aplicação das políticas, aspecto responsável pela potencialização da análise no sentido de capturar as contradições e as singularidades contidas entre o processo de formulação e de efetivação das políticas.

No contexto de regulação social pós-burocrática, no campo educacional, com significativa inserção dos princípios da Nova Gestão Pública, o papel dos diretores escolares torna-se ainda mais complexo, sendo obrigados a se adaptar às orientações gerenciais estabelecidas pelos órgãos governamentais, a responder aos compromissos administrativos, distribuir o coletivo escolar na nova estrutura organizacional e submeter a comunidade escolar aos procedimentos avaliativos de desempenho e, ao mesmo tempo, lidar com as contradições relativas à dimensão da gestão, dos processos educativos e das relações de poder no espaço escolar.

Segundo Barrère (2013), os diretores sentem-se obrigados a fazer a escola funcionar. Isso significa ter uma atitude de aglutinador de forças ou conduzir os docentes em projetos comuns na escola. $\mathrm{Na}$ prática, o diretor precisa engajar os professores e fazer funcionar as ações na escola, seja reduzir as repetições, melhorar os índices de desempenho ou estimular projetos comuns. A autora esclarece que os diretores escolares são considerados peças centrais de um movimento de modernização organizacional em que eles são responsáveis pela implementação na gestão escolar, fazendo com que os professores participem desse movimento.

Nesse sentido, Barrère (2013) descreve possíveis status de diretores escolares, a saber: o diretor burocrata, que se mantém apegado às regras formais e burocráticas, apesar de evidente contradição com os atuais parâmetros de gestão escolar, esse diretor permanece apegado à ordem estabelecida e ao controle burocrático oficial; o diretor expert, que utiliza de forma eficiente os conhecimentos práticos advindos da experiência profissional, no campo 
pedagógico e administrativo, constituindo uma expertise local eficaz para lidar com os problemas cotidianos; o diretor coach, que se constitui por meio de procedimentos de controle atenuados sob a forma de auxílio, de escuta e de acompanhamento dos professores, que tende a confundir a intenção hierárquica de controle e a ajudar os professores na resolução de problemas pedagógicos. Por fim, a autora descreve o diretor político, que se caracteriza pela disposição de construir alianças políticas, negociadas e flexíveis, visando delegar uma parte de seu poder aos pares, numa estratégia próxima à do empowerment, cujo sentido é a participação de um maior número de atores na organização e no controle da atividade.

Evidentemente esses status constituídos a partir dos novos parâmetros de regulação sofrem hibridizações, mas podem ser considerados como perfis relevantes para compreendermos como os diretores escolares tendem a se comportar no contraditório processo de gestão escolar, em suas especificidades, em um contexto permeado pela existência de procedimentos de regulação ainda em transformação. No caso específico de Goiás, a implementação da reforma educacional articulada aos fundamentos da descentralização e aos princípios da responsabilização deu-se com as diretrizes gerais do Pacto pela Educação, em especial, por meio, do Programa Reconhecer e do Sistema de Avaliação Educacional do Estado de Goiás (Saego), cujo objetivo foi alterar o modelo de gestão e avaliação praticado no sistema estadual de ensino.

\section{DIVERSIFICAÇÃO E CONTROLE: O PERFIL DO SISTEMA DE ENSINO E OS PROGRAMAS EDUCACIONAIS EM ANÁLISE}

O processo de reforma educacional, em Goiás, inicia-se em 2011, com a apresentação do documento Pacto pela Educação: um futuro melhor exige mudanças. Esse documento lançado no governo de Marconi Perillo (2010-2014) contém diretrizes e orientações concernentes à gestão, ao currículo e ao processo de avaliação realizados na estrutura educacional do sistema estadual de ensino ${ }^{4}$. O Pacto pela Educação efetiva-se como política pública ao instituir uma nova perspectiva teórica responsável pela disseminação de procedimentos e parâmetros ligados aos princípios da responsabilização e da meritocracia na educação pública estadual (GOIAS. SEDUCE, 2011).

\footnotetext{
4 O Pacto pela Educação estrutura-se por meio de cinco eixos e 25 ações. Os eixos intitulam-se, seguindo a ordem, do primeiro ao quinto: Valorizar e fortalecer o profissional da educação; Adotar práticas de ensino de alto impacto no aprendizado; Reduzir significativamente a desigualdade educacional; Estruturar o sistema de reconhecimento e remuneração por mérito e Reforma na gestão e na infraestrutura da rede estadual de ensino (GOIAS. SEDUCE, 2011).
} 
Em sintonia com os preceitos teóricos do Pacto pela Educação, nos últimos anos, instituiu-se na estrutura do sistema estadual de ensino um intenso processo de diversificação da oferta educacional com a existência de um sistema público articulado a convênios com a iniciativa privada. Em 2019, o número de instituições privadas conveniadas com a rede estadual atingiu a cifra de 61 unidades, sendo a maioria dos convênios firmados com instituições especializadas na oferta de educação especial e educação profissional. Salienta-se também a crescente diversificação do sistema de ensino com as organizações sociais, responsáveis pela gestão das instituições de ensino profissionalizante e, as escolas com padrão militar de gestão, que crescem vertiginosamente no sistema estadual de ensino de Goiás, em 2019, a quantidade de escolas militarizadas atingiu a cifra de 59 instituições distribuídas em 45 municípios goianos (GOIÁS. SEDUC, 2020).

Em relação às características diversificadas do sistema pode-se destacar que a maioria dos convênios firmados com instituições especializadas na oferta de educação especial e educação profissional constituiu-se com instituições religiosas e/ou filantrópicas. No caso das escolas militarizadas, em parceria com sistema estadual de ensino, trata-se de um padrão de gestão e currículo escolar baseado na disciplina e na hierarquia militar, adaptado ao perfil e estrutura física das escolas públicas estaduais, modelo instituído no sistema de ensino, com maior intensidade, entre os anos de 2013 e 2017, por meio de parceria entre o sistema estadual de ensino e a Polícia Militar, associado à cobrança de taxas de matrículas dos estudantes (GOIÁS. SEDUC, 2020; ALVES; TOSCHI; FERREIRA, 2018).

Destaca-se nesse contexto, a tendência de aumento da participação do sistema privado de ensino na oferta de matrículas, com um total de 98.002 distribuídas nos anos finais do ensino fundamental e ensino médio. Se considerarmos o conjunto das etapas da Educação Básica em Goiás, a saber, a Educação Infantil, Anos Iniciais do Ensino Fundamental, os Anos Finais e o Ensino Médio, o total de matrículas em 2019, no sistema privado de ensino, alcança o número de 278.532 matrículas 5 . O que demonstra uma forte demanda não atendida pelo conjunto do setor público. Esse padrão diversificado no formato de convênios com o sistema público pode assumir diversas configurações, tanto com procedimentos de parcerias subvencionadas pelo governo estadual que não exigem contrapartida direta dos estudantes, como pelo modelo demonstrado no padrão de escolas de gestão militar subsidiadas com recursos públicos e privados, na forma de pagamento das taxas de matrícula (BRASIL, 2019).

\footnotetext{
5 Apenas para compararmos a dimensão do crescimento do sistema privado, de acordo com o Censo Escolar, em 2019, o sistema público registrou, incluindo todos os segmentos e modalidades nas diversas dependências administrativas 1.447.842 matrículas na Educação Básica do Estado de Goiás. Desse total geral, foram matriculados 489.327 alunos na dependência administrativa estadual (BRASIL, 2019).
} 
Observa-se que as políticas públicas educacionais implementadas, por meio, do Pacto pela Educação, além de disseminarem a responsabilização e a meritocracia como princípios à serem aplicados na gestão das escolas públicas estaduais, também promoveram a alteração de uma lógica de funcionamento do setor público com o estímulo a convênios e parcerias com o setor privado. Tratase de um processo simultâneo de alteração do padrão de gestão pública e de indução as parcerias. Salienta-se que a transferência de parte das responsabilidades educativas do estado para o setor privado, em especial, nas modalidades mais onerosas, como a educação especial e o ensino profissionalizante, bem como a indução de procedimentos gerenciais e de semi-privatização na condução dos assuntos educacionais representa uma grande alteração da dinâmica educativa do sistema de ensino ao instituir parâmetros privados como referência para a condução dos serviços públicos.

Em relação aos efeitos do Pacto pela Educação, a pesquisa de Almeida (2018) revela que a reforma educacional realizada em Goiás, por meio, do Pacto pela Educação intensificou a perda de direitos adquiridos pelos professores da rede estadual de ensino condicionando-os a uma situação de maior desprofissionalização e precarização nas condições de trabalho. Nesse mesmo sentido, Pessoni (2017) demonstra que o Pacto pela Educação efetiva como política pública, os parâmetros e a concepção de educação defendida pelos organismos internacionais. As orientações educacionais presentes nos documentos do Banco Mundial e nas declarações mundiais formuladas pela Unesco contêm uma concepção a respeito do processo de descentralização da gestão escolar, das avaliações de larga escala e dos critérios de qualidade associados à avaliação que se materializa como política pública, por meio desse documento, no Estado de Goiás.

Em sintonia com o processo de reforma educacional, o Programa Reconhecer (2011) institui a política de bônus na estrutura do sistema estadual de ensino. A intenção inicial descrita nas leis que definiram o pagamento de bônus de incentivo aos profissionais da educação era estimular o trabalho de regência de sala de aula e, por esse motivo, previa o pagamento de remuneração adicional aos professores e professoras da Educação Básica a partir do critério de assiduidade e de entrega quinzenal do plano de ensino $0^{6}$. Nos anos subsequentes à criação do bônus para o pagamento dos professores e das professoras, a secretaria estadual de educação definiu para o grupo gestor da escola um índice de acompanhamento da gestão que incluiu, entre outros critérios, o controle do trabalho realizado pelos professores e professoras regentes e coordenadores e coordenadoras pedagógicos,

6 A partir do ano de 2012, a Seduce-GO ampliou o número de profissionais da educação beneficiados pelo Programa Reconhecer, ao incluir no pagamento do bônus, os coordenadores e coordenadoras pedagógicos, o grupo gestor e os tutores e tutoras pedagógicos. 
em especial no que concerne à assiduidade e à entrega dos planos de aulas, além de definir como responsabilidade desse grupo, o lançamento da frequência dos profissionais da educação no sistema interno de controle da gestão escolar, aspectos considerados obrigatórios para o recebimento do bônus de incentivo salarial (GOIAS, 2013).

Moura (2016) analisa os efeitos indutivos do Programa Reconhecer, de reconhecimento e remuneração por mérito, na constituição dos valores da meritocracia, da competitividade, da responsabilização e do controle por incentivo/ punição presentes na reforma educacional. Segundo a autora, esse movimento contido no processo de reforma contém uma perspectiva neotecnicista de educação ao disseminar uma visão de educação sedimentada sobre os princípios da racionalização das práticas educativas submetidas a procedimentos de avaliação de larga escala, de currículo padronizado, de responsabilização, de meritocracia e de competitividade entre os agentes escolares, com o objetivo de induzir na gestão pública, os mesmos princípios defendidos pela iniciativa privada.

O processo de descentralização articulado aos parâmetros da responsabilização e meritocracia somente se desenvolveu plenamente com a criação das políticas de avaliação em larga escala, capazes de definir objetivos de proficiência para o desempenho dos alunos e das escolas. Com o objetivo de implementar essa política na Educação Básica em Goiás, foi formulado o Sistema de Avaliação Educacional do Estado de Goiás (Saego), em 2011, com o objetivo de produzir diagnósticos sobre o nível de proficiência dos alunos matriculados na rede estadual de ensino e nas escolas particulares conveniadas. O estudo de Melo (2018) realizado com diretores escolares do sistema estadual de ensino de Goiás, demonstra a percepção dos dirigentes a respeito das alterações no cotidiano escolar após o desenvolvimento dos procedimentos de avaliação em larga escala instituído nas escolas públicas. A pesquisa realizada por Melo (2018) revela que o Ideb provocou diversas mudanças na gestão escolar e a constante preocupação dos diretores em executar ações com vistas a atingir as metas estabelecidas pela Seduce. Na prática, as avaliações de larga escala projetadas pelo governo nacional e estadual comprometem a autonomia dos diretores na condução da gestão escolar, pois suas ações administrativas e orientações pedagógicas devem se pautar pelos resultados dos processos avaliativos e expectativas de desempenho dos alunos, culminando na intensificação do controle e regulação do trabalho por parte da Seduce.

Salienta-se que a associação entre os resultados educacionais nos testes avaliativos e a capacidade de gestão dos diretores escolares foi instituída pela própria Seduce, por meio da Portaria no 2783 de 2011, que regulamenta o processo de eleição dos diretores no sistema estadual de ensino, ao estabelecer a 
exoneração dos diretores eleitos, em caso de não cumprimento das metas do Ideb ou da não aprovação de sua gestão em processo de avaliação de desempenho (GOIAS, 2011). Observa-se que as políticas de responsabilização são aplicadas na estrutura do sistema estadual de ensino com efetivas implicações sobre o trabalho do diretor e do grupo gestor, em geral associadas aos procedimentos avaliativos, cujo sentido é fortalecer uma perspectiva de educação sedimentada sobre os valores da meritocracia e da responsabilização como referência para a gestão das instituições públicas de ensino (SILVA, ALVES, 2012).

\section{DIRETORES ESCOLARES: ENTRE AS ESTRUTURAS DE CONTROLE E AS CONTRADIÇÕES NA GESTÃO DOS PROCESSOS EDUCATIVOS}

As análises realizadas neste tópico têm como referência as respostas dos 91 diretores escolares ao questionário elaborado, por meio, da Plataforma Forms e enviado via e-mail institucional da Seduce aos dirigentes de escolas públicas estaduais, destacando-se as partes do questionário cujo objeto de investigação foram o perfil acadêmico e profissional do diretor escolar, a gestão da escola e os efeitos do programa Reconhecer e do Saego no trabalho do diretor.

Em relação ao perfil acadêmico dos diretores, a maioria possui graduação em cursos de licenciatura (89\%) e curso de pós-graduação lato sensu de 360 horas $(69 \%)$. Os cursos de pós-graduação lato sensu oferecidos em instituições privadas de ensino predominam como nível final de formação da maioria dos participantes da pesquisa. Em geral, a Seduce oferece cursos de formação continuada direcionados à formação administrativa e pedagógica. No tocante ao curso de formação para gestores oferecido pela Seduce, a maioria dos diretores ( $90 \%$ ) o avaliaram como positivo, pois o curso contribuiu decisivamente para a realização da gestão financeira, administrativa e pedagógica da escola. Entretanto, a complexa natureza dos processos educativos e a especificidade da instituição escolar, extrapolam a dimensão restrita de formação continuada destinada a suprir os conhecimentos técnicos necessários para a resolução de problemas cotidianos, pois essa perspectiva de formação tende a ofuscar uma leitura mais crítica concernente à realidade escolar e às potencialidades transformadoras contidas no trabalho educativo.

No que concerne ao perfil profissional, a maioria dos diretores já ocuparam a função de coordenadores pedagógicos (58\%) ou funções administrativas (61\%) na escola em que trabalham ou em outra escola do sistema estadual de ensino. Essa informação destaca que muitos diretores, antes de assumirem a função, já possuíam algum tipo de experiência nas funções pedagógicas e administrativas. No 
entanto, os dados também revelam um quantitativo relativamente alto de diretores inexperientes: do total de 91 participantes, respectivamente, $42 \%$ não possuem experiência pedagógica e 39\% não possuem experiência administrativa anteriores ao exercício da função diretiva. Esses resultados reforçam a importância de cursos de formação continuada, pois há um número expressivo de diretores que não têm experiência com projetos pedagógicos ou trabalhos multidisciplinares, bem como conhecimento técnico relativo ao trabalho administrativo.

Em relação à gestão democrática, os diretores foram questionados a respeito do processo de tomada de decisões, mais precisamente, se a gestão da escola obedece a um processo coletivo de discussão e definição das ações. Os participantes também foram abordados sobre a possibilidade de desenvolver práticas de gestão democrática na escola, mesmo com a pressão para alcançar bons resultados nas avaliações. A maioria dos diretores deu respostas afirmativas em relação à disposição de desenvolverem práticas coletivas de discussão (98\%) e democráticas (91\%) pertinentes ao processo de tomada de decisões, mesmo com a pressão relativa aos resultados. No entanto, quando questionados a respeito dos objetivos da escola, mais especificamente, se os projetos multidisciplinares e a intensificação do diálogo com a comunidade escolar teriam sido substituídos pelo alcance de resultados nas avaliações, a resposta da maioria dos diretores também foi afirmativa $(61 \%)$.

As respostas a essas questões demonstram que os procedimentos de avaliação em larga escala tendem a interferir na disposição dos diretores de desenvolverem práticas coletivas e democráticas envolvendo o conjunto da comunidade escolar relativo ao processo de tomada de decisões. Na prática, os procedimentos de avaliação tendem a sacrificar o processo de gestão democrática e coletiva nas escolas, ao sobrepor a autonomia pedagógica e o aprofundamento de relações consensuais aos parâmetros avaliativos.

Ao serem questionados a respeito dos empecilhos para a tomada de decisões mais coletivas na escola, a maioria dos diretores (46\%) assinalou a urgência nas decisões administrativas, a dificuldade de reunir os grupos a tempo e o fato de os assuntos já chegarem na escola previamente decididos, dispensando decisões coletivas. A análise desses empecilhos pode nos dar pistas a respeito da fragilidade dos processos coletivos de decisão. Na prática, a Seduce tende a influenciar as decisões do grupo gestor das escolas, fenômeno que acontece por meio de orientações legais, recomendações burocráticas ou ordens provenientes de membros do alto escalão da hierarquia da Seduce que podem interferir na decisão do diretor e do coletivo escolar. Em muitas circunstâncias as decisões já chegam na escola previamente definidas pelas orientações da estrutura burocrática, ou a urgência das decisões podem inviabilizar as possibilidades de práticas mais 
democráticas. Em relação a ausência de pessoas dispostas a participar, esse fenômeno pode ser explicado pelo pouco efeito deliberativo das decisões tomadas na escola.

Em relação ao programa Reconhecer, que prevê o pagamento de remuneração adicional aos professores e demais profissionais da escola a partir do critério de assiduidade e de entrega quinzenal do plano de ensino, os diretores (86\%) afirmam que sempre ou frequentemente há cobranças para os professores entregarem os planos em dia. Evidentemente, o diretor cumpre a tarefa de acompanhar a entrega dos planos e a frequência dos professores, pois trata-se de um critério para o recebimento do bônus atribuído ao grupo gestor da escola.

$\mathrm{Na}$ realidade, os procedimentos de controle e monitoramento intensificaram-se durante o processo de reforma educacional. Após o ano de 2011, a Seduce aperfeiçoou os sistemas de informação, como o Sistema de Gestão Escolar (SIGE) ${ }^{7}$ e o Sistema Administrativo e Pedagógico (SIAP 360) ${ }^{8}$ com o objetivo de monitorar informações e a gestão do sistema de ensino. Quando questionados a respeito dos impactos dos sistemas de informação sobre o funcionamento da gestão e o trabalho do grupo gestor, a maioria (41\%) afirma que não houve impactos, mas uma parte razoável de diretores (21\%) afirmou ter percebido o aumento do volume de trabalho administrativo e a preocupação com a coleta diária de informações relativas à frequência dos professores e coordenadores.

No tocante a rotina administrativa realizada anteriormente na escola, a maioria dos diretores (74\%) afirmou que as políticas de reconhecimento por mérito (bônus) implementadas pela Seduce não a alteraram demasiadamente. Entretanto, um grupo de 22 diretores (24\%) participantes discorda da opinião da maioria, ao afirmar que houve alterações na rotina administrativa. Quando questionados se as políticas de reconhecimento por mérito (bônus) implementadas pela Seduce alteraram demasiadamente a autonomia e a gestão pedagógica realizada anteriormente na escola, a maioria (81\%) afirmou que não houve nenhuma alteração substantiva nesse campo. Todavia, um pequeno grupo de 11 diretores (12\%), de um total de 91 participantes, afirma ter alterado demasiadamente a autonomia e a gestão pedagógica da escola. Já um restrito grupo de 6 participantes (7\%), não soube responder. A análise das respostas das duas questões combinadas, considerando o emprego do adjetivo 'demasiadamente' na

7 O SIGE (Sistema de Gestão Escolar) é um sistema próprio de planejamento, processamento dos dados e suporte criado pela Secretaria de Educação de Goiás. A frequência diária do aluno, o controle do Programa Reconhecer e a Avaliação Diagnóstica são realizados por meio do SIGE (GOIÁS, SEDUC, 2020).

8 OSIAP (Sistema Administrativo Pedagógico) é um sistema criado para ser utilizado pelos professores no uso do diário eletrônico, pela unidade escolar e Coordenadorias Regionais. O sistema permite o controle da frequência, o cadastro das notas e o controle das avaliações realizadas pelos alunos (GOIÁS, SEDUC, 2020). 
formulação das questões, esclarece que a política de bônus tende a interferir, de alguma maneira, na dinâmica de gestão da escola, pois houve alterações na rotina administrativa, na autonomia e na gestão pedagógica da escola.

Em relação aos conflitos, a maioria dos diretores (58\%) afirma que não houve manifestação de oposição aos procedimentos de monitoramento e controle implementados pelo Programa Reconhecer. No entanto, um grupo razoável de 37 participantes (41\%) afirma o contrário. Os conflitos com os professores aparecem de forma mais explícita, em razão da política de bônus não aceitar nenhum atestado médico para compensar as ausências dos docentes. Quando questionados de que forma os conflitos entre os professores e a direção mais aparecem concernentes às políticas de avaliação e de pagamento de bônus implementadas pela Seduce, os diretores reafirmam que não houve conflitos (54\%). Os poucos conflitos, assinalados pelos diretores, revelam que eles estão ligados a críticas à direção da escola associadas aos procedimentos de monitoramento (16\%) estabelecidos pela Seduce e a reclamações à direção, pertinentes ao excesso de controle da frequência dos professores (11\%). Na realidade, tratam-se de críticas indiretas à Seduce, que se manifestam em conflitos diretos com os diretores responsáveis pela implementação das políticas na escola.

Em relação aos procedimentos de avaliação, os diretores dividem-se em suas respostas de concordância (39\%) e discordância (58\%), ao analisarem ser o Saego o principal instrumento que subsidia e motiva as ações de intervenção pedagógica na escola, considerando um pequeno grupo de 3\% dos diretores que não responderam à questão. Ao serem questionados a respeito do Saego ser o principal sistema de monitoramento e avaliação das ações pedagógicas realizadas na escola, os respectivos percentuais, $40 \%$ de concordância e $56 \%$ de discordância e 3\% de abstenção revela a dificuldade dos diretores de analisar o processo. O equilíbrio entre as respostas dos participantes demonstra que talvez o Saego não seja o principal instrumento, mas que tem interferência na formulação, motivação e avaliação das ações pedagógicas da escola. O Saego influencia por instituir práticas pedagógicas subordinadas aos procedimentos avaliativos. Assim, o Saego é considerado, por uma parte considerável dos diretores, como um instrumento motivador e avaliador das ações pedagógicas, além de interferir na prática pedagógica da escola por meio de um viés avaliativo baseado em resultados e, dessa forma, distancia uma concepção de educação mais crítica destinada à formação para a cidadania.

Segundo a maioria dos diretores (80\%), os resultados do Saego representam um instrumento de monitoramento e avaliação do trabalho realizado por eles na escola. Quando questionados a respeito de que forma as políticas avaliativas (Saego) mais interferiram na gestão pedagógica da escola, os diretores 
afirmam que, por instituir uma contínua preocupação entre os professores, os coordenadores e o grupo gestor concernente à elaboração de estratégias voltadas para a melhoria do desempenho dos alunos nas avaliações $(21 \%)$ e por instaurar um planejamento pedagógico baseado em metas e resultados $(20 \%)$. A resposta dos diretores demonstra que os procedimentos avaliativos, ao mesmo tempo que restringem o processo de aprendizagem subordinados a resultados, também representam o aumento da demanda pedagógica sobre os diretores, vistos como estimuladores de práticas pedagógicas ou estratégias capazes de melhorar o desempenho dos alunos nas avaliações. Nesse mesmo sentido, quando questionados a respeito das medidas que a gestão da escola toma quando o padrão de desempenho aferido nas avaliações é inferior ao definido pela meta da escola, a maioria dos diretores (47\%) afirma discutir com o coletivo de professores os resultados e novos procedimentos pedagógicos, buscando investir na elaboração de estratégias pedagógicas mais voltadas para as dificuldades pontuais dos alunos.

\section{CONSIDERAÇÕES FINAIS}

Os estudos realizados permitiram identificar como o programa Reconhecer e o Sistema de Avaliação Educacional do Estado de Goiás (Saego), interferiram na gestão da escola pública e no trabalho do diretor escolar. Ao instituir procedimentos de monitoramento e controle, o programa Reconhecer tende a gerar relações de maior controle e padronizar o trabalho pedagógico dos professores. Ações intensificadas com o aperfeiçoamento dos sistemas de informação, capazes de controlar a frequência e os conteúdos trabalhados pelos docentes.

Em relação à articulação da gestão da escola com os procedimentos de avaliação, o Saego tende a padronizar as ações docentes destinadas a melhorar o desempenho dos estudantes nas avaliações de larga escala. Evidentemente, esse processo de padronização tende a sacrificar o processo de gestão democrática nas escolas, ao sobrepor a autonomia pedagógica e o aprofundamento de relações consensuais aos parâmetros avaliativos. As contradições aparecem quando se analisa a disposição dos diretores em instituir práticas coletivas, apesar do enfraquecimento dos princípios democráticos, em razão dos instrumentos de controle existentes subsumidos aos parâmetros avaliativos.

Salienta-se que, nesse mesmo contexto, os diretores também são estimulados a engajarem os professores em torno de ações pedagógicas e conduzirem um esforço coordenado destinado a melhorar o desempenho dos alunos nas avaliações. Apesar dos restritos objetivos contidos, nessa proposição, a ainda existente disposição democrática dos diretores e a especifidade do trabalho 
educativo pode conter possibilidades de retomada de ações pedagógicas com uma perspectiva mais abrangente relativa a formação destinada a cidadania. Parece que entre os diretores ainda há uma percepção de que o trabalho coletivo e articulado do ponto de vista pedagógico, é o caminho para os alunos efetivamente aprenderem.

As contradições se revelam, na gestão da escola, entre a pressão da Seduce pela melhoria dos resultados nas avaliações, associada à padronização dos conteúdos, ao mesmo tempo em que os diretores precisam "fazer a escola funcionar", ou seja, unir os docentes em torno de um projeto pedagógico comum capaz de conduzir ao aprendizado (BARRÈRE, 2013). Esse contraditório contexto, situado entre o alcance de resultados de aprendizagem identificados nas avaliações de larga escala responsáveis pela padronização dos conteúdos e das ações pedagógicas, bem como pelo enfraquecimento de práticas coletivas e democráticas na escola, defronta-se com a necessidade, apesar de também ser direcionada aos objetivos de alcance dos resultados, de diretores engajarem e unirem os docentes em torno de um projeto pedagógico comum ou conduzirem ações de aprendizagem com efeitos pedagógicos, a curto ou médio prazo, que podem intensificar as contradições próprias da natureza da trabalho pedagógico e a potencialidade de práticas coletivas capazes de desenvolver perspectivas de educação mais abrangentes.

\section{REFERÊNCIAS}

ALMEIDA, Rosivaldo Pereira de. Armadilhas no labirinto: escolarização e trabalho docente desafiados pelo Pacto da Educação em Goiás. 2018. 221 f. Tese (Doutorado). Programa de Pós-Graduação em Educação - Faculdade de Educação da Universidade Federal de Goiás, Goiânia, 2018.

ALVES, Miriam Fábia; TOSCHI, Mirza Seabra; FERREIRA, Neusa Sousa Rêgo. A expansão dos colégios militares em Goiás e a diferenciação na rede estadual. Retratos da Escola, v. 12, n. 23, p. 271-288, 2018.

BARROSO, João. La gestion scolaire, entre modernisation et exigence democratique. Revue internationale d'éducation de Sèvres, $n^{\circ}$ 60, septembre 2012.

BARROSO, João. O Estado, a Educação e a regulação das políticas públicas. Educação \& Sociedade. Campinas, vol. 26, n. 92, p. 725-751, Especial, Out. 2005. 
BARRÈRE, Anne. Controlar ou avaliar o trabalho docente? Estratégias dos diretores numa organização escolar hibrida. Revista Brasileira de Educação. v. 18, n. 53, abril-junho 2013.

BRASIL. Lei de Diretrizes e Bases da Educação Nacional. Lei nº 9394/96, de 20 de dezembro de 1996. Brasília. Subsecretaria de Edições Técnicas, 2002.

BRASIL. Constituição da República Federativa do Brasil. 05 de Outubro de 1988. Brasília: Senado Federal, Subsecretaria de Edições Técnicas, 2000.

BRASIL. MEC. INEP. Sinopse Estatística da Educação Básica. Brasília, 2019. Disponível em: http://portal.inep.gov.br/sinopses-estatisticas-da-educacaobasica. Acesso em: 10 mar. 2020.

GOIÂNIA. Mapa Urbano Básico Digital de Goiânia - MUBDG v.23 - 2012.

GOIÁS. SEDUC. Site oficial da Secretaria de Estado de Educação. Escolas detalhadas. Disponível em: https://site.seduce.go.gov.br/pesquisa-de-escolasdetalhada/. Acesso em: 21 mar. 2020.

GOIÁS, Portaria No 2783/SEDUC. Dispõe sobre os critérios para o Processo de Escolha dos Diretores das Unidades Escolares, SEDUC, Goiás, Goiânia, 2011.

GOIÁS. Lei $\mathbf{n}^{\circ}$ 18.093, de 17 de Julho de 2013. Institui, para o ano de 2013, o Bônus de Incentivo Educacional aos profissionais da educação pública estadual e dá outras providências. Goiânia, 2013.

GOIÁS. SEDUCE. Pacto pela Educação: um futuro melhor exige mudanças. 2011. Disponível em: http://www.seduc.go.gov.br/especiais/pactopelaeducacao/ docs/Microsoft PowerPoint. Acesso em: 08 fev. 2019.

MAROY, Christian; VOISIN, Annelise. As transformações recentes das políticas de accountability na educação: desafios e incidências das ferramentas de ação pública. Educação \& Sociedade. Campinas, v. 34, n. 124, p. 881-901, jul.-set. 2013.

MARTINS, Ângela Maria. A descentralização como eixo das reformas do ensino: uma discussão da literatura. Educação e Sociedade, ano XXII, n. 77, Dez, 2001. 
MELO, Viviane Pereira da Silva. Avaliação em larga escala: repercussões do IDEB na visão dos diretores de escola da rede estadual de Goiás. 2018. 182 f. Dissertação (Mestrado). Programa de Pós-Graduação em Educação - Faculdade de Educação da Universidade Federal de Goiás, Goiânia, 2018.

MOURA, Priscila de Oliveira. O Sistema de bônus/prêmio na reforma Pacto pela Educação (Seduc/Goiás 2011-2014). 2016. 112f. Dissertação (Mestrado) - Programa de Pós-Graduação em Educação - Faculdade de Educação da Universidade Federal de Goiás, Goiânia, 2016.

OLIVEIRA, Dalila Andrade; DUARTE, Alexandre Willian Barbosa; ClEMENTINO, Ana Maria. A Nova Gestão Pública no contexto escolar e os dilemas dos(as) diretores(as). RBPAE. V. 33, n. 3, p. 707 - 726, set./dez. 2017.

PESSONI, Lucineide Maria de Lima. Internacionalização das políticas educacionais, finalidades educativas escolares e qualidade de ensino: a reforma educativa no Estado de Goiás. 2017. 211f. Tese (Doutorado) - Programa de Pós-Graduação Stricto Sensu em Educação Pontifícia Universidade Católica de Goiás. Goiânia, 2017.

SANTOS, Ana Lúcia Felix; ANDRADE, Edson Francisco; MARQUES, Luciana Rosa (Orgs). Políticas educacionais no estado de Pernambuco: discursos, tensões e contradições Recife: Ed. UFPE, 2019.

SILVA, Luís Gustavo A.; ALVES, Miriam Fábia. Gerencialismo na escola pública: contradições e desafios concernentes à gestão, à autonomia e à organização do trabalho escolar. RBPAE - v. 28, n. 3, p. 665-681, set/dez. 2012.

\section{Luís Gustavo Alexandre Silva}

Doutor em Educação e Professor Associado da Faculdade de Educação da Universidade Federal de Goiás.

E-mail: luis_gustavo_silva@ufg.br

\section{Ricardo Antônio Gonçalves Teixeira}

Doutor em Educação e Professor do Programa de Pós-Graduação em Educação da Universidade Federal de Goiás (UFG).

Email: professorricardoteixeira@ufg.br 